\title{
IMPACTO DE ATIVIDADES AGROPECUÁRIAS NA QUALIDADE DAS ÁGUAS DO RIO CABEÇA, NA BACIA DO RIO CORUMBATAÍ, SP
}

\section{IMPACT OF AGRICULTURAL ACTIVITIES ON WATER QUALITY OF THE RIVER CABEÇA ('HEAD'), IN CORUMBATAÍ RIVER BASIN, SP}

\section{Eduardo Beraldo de Morais ${ }^{1}$, Sâmia Maria Tauk-Tornisielo², Silvia Elena Ventorini ${ }^{3}$}

\author{
${ }^{1}$ Professor Adjunto Universidade Federal de Mato Grosso, Departamento de \\ Engenharia Sanitária e Ambiental. Av. Fernando Correa da Costa- Coxipó, CEP: \\ 78060-900 - Cuiabá, MT \\ ${ }^{2}$ Pesquisadora do Centro de Estudos Ambientais da UNESP, Campus de Rio Claro, \\ SP.E-mail: seb@rc.unesp.br \\ ${ }^{3}$ Professora Assistente Universidade Federal de São João Del-Rei, DEGEO. Av. \\ Visconde do Rio Preto, s/n - Colônia do Bengo, CEP: 36301-360 - São João Del Rei, \\ $\mathrm{MG}$
}

\begin{abstract}
RESUMO
Os corpos hídricos na bacia do rio Corumbataí vêm apresentando alterações significativas devido ao mau uso das terras pelas atividades agropecuárias e lançamentos de efluentes domésticos e industriais. Dentre os tributários nessa bacia hidrográfica, o rio Cabeça situa-se em área explorada, principalmente, por pastagem e cultura de cana-de-açúcar. O presente estudo abordou a qualidade da água na microbacia do rio Cabeça e as possíveis fontes poluidoras. Durante 24 meses (abril de 2007 a março de 2009) sete pontos de amostragem foram monitorados, sendo cinco no rio Cabeça e dois no rio que recebe a suas águas, o rio Passa-Cinco. Segundo o Índice de Qualidade da Água (IQA), a qualidade das águas é considerada boa, mas parâmetros como demanda bioquímica de oxigênio (DBO) e Escherichia coli, utilizados no cálculo desse índice, apresentaram valores em desacordo com os limites máximos estabelecidos pela Resolução CONAMA 357/2005 para corpos hídricos de classe 2. Isso indica poluição por efluentes domésticos de vilas rurais e/ou efluentes originados da criação de animais. Verificou-se que no período chuvoso/quente (outubro a março) o aumento do escoamento superficial pode alterar os valores dos parâmetros estudados com exceção para DBO. Há necessidade de recuperação das matas ciliares em alguns trechos para diminuir o assoreamento e também maior controle das monoculturas dominantes instaladas em declives acima de $45^{\circ}$ e próximas às cavas de rios e córregos.
\end{abstract}

Palavras-chave: Rio Cabeça. Bacia do rio Corumbataí. Qualidade da água. Atividades agropecuárias. 


\begin{abstract}
The hydric bodies in the Corumbataí basin have presented significant changes, resulted from land misuse by agricultural activities and domestic and industrial sewage discharge. Among the tributaries in this basin, the River 'Head' is located in areas occupied, principally, by pasture and sugar cane crops. This study aimed water quality in the River 'Head' micro basin, and possible pollution sources. During 24 months (April 2007 to March 2009) seven sampling stations were monitored, five in the River 'Head' and two in the river which receives its water, the Passa-Cinco River. According to Water Quality Index (WQI), the water quality is considered Good, but the values of parameters biochemical oxygen demand (BOD) and Escherichia coli, using in calculating this index, were discordance with that established by CONAMA 357/2005 Resolution to class 2 hydric bodies. This indicates pollution by wastewater from rural village and/or breeding effluents. It was found during the rainy/warm season (October-March) the runoff increased can influence the parameters values studied except for BOD. It is necessary the recovery the riparian forests in some places to reduce siltation and control of the dominant monoculture installed on slopes above 45 degrees and close to rivers and streams beds.
\end{abstract}

Keywords: Cabeça 'Head' river. Corumbataí basin. Water quality. Agricultural activities.

\title{
1. INTRODUÇÃO
}

O monitoramento dos parâmetros da qualidade das águas superficiais se constitui em importante instrumento da gestão ambiental (BOUZA-DEAÑO et al., 2008), haja vista que subsidia a tomada de decisões em planejamento e controle dos usos das mesmas, visando à manutenção ou melhoria da qualidade de vida da população (NIKAIDO et al., 2004).

A bacia do rio Corumbataí, no estado de São Paulo, assume importância econômica e social por apresentar potencial hídrico capaz de abastecer as cidades de Analândia, Corumbataí, Rio Claro, Santa Gertrudes, Ipeúna, Itirapina e Charqueada e ainda permitir a exportação de água para municípios localizados em bacias vizinhas, tais como Araras e Piracicaba, onde os problemas hídricos são bastante sérios (MORAIS, 2010).

Os principais afluentes na bacia do rio Corumbataí são os rios Cabeça, Passa-Cinco e Ribeirão Claro além de corpos hídricos menores como córregos da Servidão, Assistência e São Joaquim. Diversos estudos abordando temas setoriais envolvendo, de modo total ou parcial, o território pertencente à bacia do rio Corumbataí, já foram realizados. Destacam-se os estudos na microbacia do Ribeirão Claro (PINTO e MAURO, 1985; HENRY-SILVA e CAMARGO, 2000; GERTEL et al., 2003); na microbacia do Passa Cinco (GARCIA et al., 2006; COMIN et al., 2009) e no rio principal, o rio Corumbataí (ARMAS et al., 2007; CETRA e PETRERE JR, 2007; PALMASILVA et al., 2007). Há um consenso nesses estudos que a bacia do rio Corumbataí vem apresentando alterações significativas devido ao não planejamento do uso da terra pelas atividades agropecuárias e pelos lançamentos de efluentes domésticos e industriais.

O rio Cabeça é afluente do rio Passa Cinco que por sua vez é afluente do rio Corumbataí. Apesar dos inúmeros estudos realizados na bacia do rio Corumbataí citados anteriormente, aqueles envolvendo a microbacia do rio Cabeça, cujo uso de suas terras é principalmente para atividades agropecuárias, ainda não suficientes para oferecer conhecimento das reais condições referentes à qualidade e quantidade de suas águas. Desta forma, o presente estudo avaliou as questões que envolvem a qualidade da água e as fontes poluidoras na microbacia do rio Cabeça, SP, com o intuito de fornecer informações para a gestão ambiental desta microbacia e consequentemente a gestão da bacia do rio Corumbataí. 


\section{MATERIAL E MÉTODOS}

\subsection{Características da área de estudo}

A bacia do rio Corumbataí situada na porção centro-leste do Estado de São Paulo possui áreas industriais e densamente povoadas como é o caso do município de Rio Claro e também é intensamente utilizada para atividades agropecuárias principalmente na área de estudo, a microbacia do rio Cabeça. Esta possui aproximadamente $214 \mathrm{~km}^{2}$ de extensão, sendo 30,5\% de sua área utilizada para a cultura de cana-de-açúcar e 39,1\% para pastagem (Tabela 1).

Tabela 1 - Usos preponderantes da terra na microbacia do rio Cabeça para o ano de 2008.

\begin{tabular}{ccc}
\hline Usos da Terra - Classes & $\mathbf{K m}^{\mathbf{2}}$ & Porcentagem (\%) \\
\hline Pastagem & 83,91 & 39,13 \\
Cana-de-açúcar & 65,44 & 30,52 \\
Cerrado & 3,54 & 1,65 \\
Cultura Perene & 5,06 & 2,36 \\
Vegetação Nativa & 39,15 & 18,26 \\
Reflorestamento & 15,67 & 7,31 \\
Área Urbana & 0,54 & 0,25 \\
Corpo d' água & 0,21 & 0,10 \\
Solo exposto & 0,92 & 0,43 \\
SOMA & $\mathbf{2 1 4 , 4 3}$ & $\mathbf{1 0 0 , 0 0}$ \\
\hline
\end{tabular}

Fonte: Morais (2010).

Geologicamente, a microbacia do rio Cabeça é composta por rochas sedimentares e vulcânicas das eras Paleozóicas (Grupo Passa Dois: Formações Corumbataí e Irati), Mesozóicas (Grupo São Bento: Formações Pirambóia, Botucatu e Serra Geral) e Cenozóica (Formação Rio Claro e depósitos recentes). $\mathrm{Na}$ maior parte da microbacia há predomínio de solos podzólico avermelhado amarelo e latossolo vermelho escuro (MORAIS, 2010). O clima é do tipo CWA (w: seca no inverno, a: mês mais quente com temperatura superior a $22^{\circ} \mathrm{C}$ ). A área pode ser enquadrada dentro de um clima tropical com duas estações bem definidas, alternadamente seca e úmida (MONTEIRO, 1973).

\subsection{Pontos amostrais}

Ao longo do rio Cabeça foram estabelecidos cinco pontos de amostragem denominados de P1 a P5 além de outros dois no rio Passa Cinco, um anterior (P6) e outro posterior (P7) ao recebimento das águas do rio Cabeça (Figura 1). Nas áreas adjacentes a P1 e P2 há predomínio de pastagem, enquanto que nos pontos $\mathrm{P} 4$ a P7 predomina a cultura de cana-de-açúcar. No local do P3 existe uma área de transição com a presença de ambas as atividades agropecuárias. 


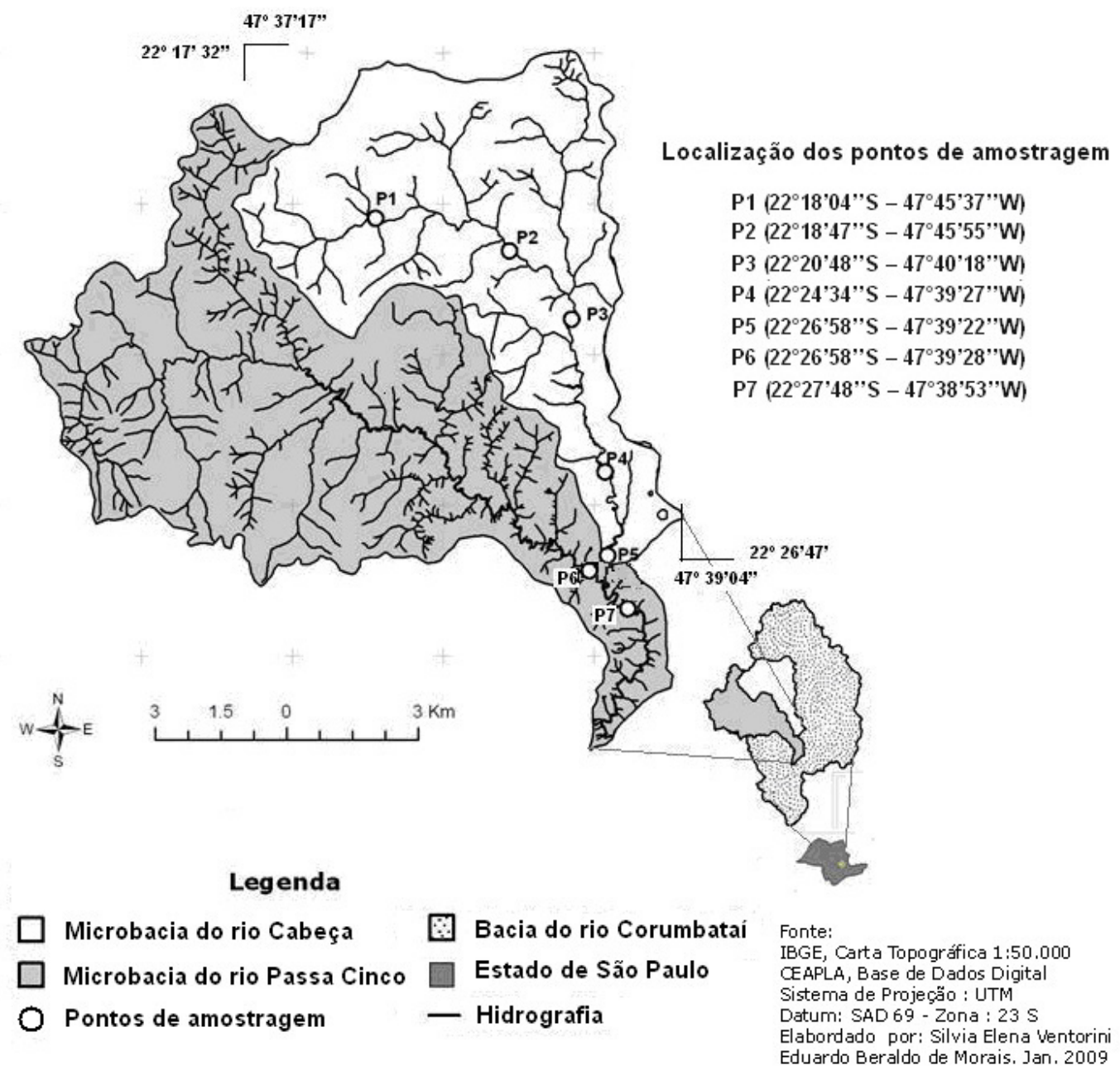

Figura 1. Localização da área de estudo na bacia do rio Corumbataí e pontos de amostragem.

\subsection{Metodologia analítica}

Mensalmente durante o período de abril de 2007 a março de 2009, as amostras de água foram coletadas em cada ponto de amostragem na metade do corte transversal da calha principal do rio, aproximadamente a $20 \mathrm{~cm}$ da superfície da água, utilizando-se amostrador de Van Dorn. As coletas foram realizadas no período da manhã entre 7:00 e 11:00 horas. Frascos de polietileno foram utilizados para o armazenamento das amostras, após serem lavados previamente com as mesmas antes da coleta definitiva. A Tabela 2 apresenta os fatores analisados, as técnicas analíticas empregadas e as respectivas unidades de medidas. Temperatura (Temp), condutividade elétrica (CE), pH, oxigênio dissolvido (OD) e sólidos totais dissolvidos (STD) foram determinados imediatamente após as coletas, com auxílio de uma Sonda Multiparâmetros marca YSI, modelo 556 MPS. Os frascos com as amostras foram transportados em caixas térmicas com gelo até o laboratório para a determinação dos demais fatores: turbidez (Turb), cor aparente (Cor Ap), demanda bioquímica de oxigênio (DBO), fósforo total (PT), amônia $\left(\mathrm{NH}_{4}\right)$, nitrato $\left(\mathrm{NO}_{3}{ }^{-}\right)$, nitrogênio total (NT) e material em suspensão (MS). Para a análise microbiológica, coliformes totais (Col Tot) e Escherichia coli (E. coli), as amostras foram armazenadas em frascos de $250 \mathrm{~mL}$ previamente esterilizados, devidamente fechados, sendo a tampa envolvida com papel protetor. As análises foram realizadas em triplicata excetuando os fatores microbiológicos, $\mathrm{pH}, \mathrm{DBO}$, material em suspensão e aqueles relacionadas ao nitrogênio. Dos dados em triplicata obteve-se a média 
aritmética. A determinação dos fatores seguiu os procedimentos e métodos de análises preconizados pelo Standard Methods for the Examination of Water and Wastewater (APHA, 1998).

Para a análise dos fatores encontrados utilizou-se como referência a Resolução CONAMA 357 de 2005 (BRASIL, 2005).

Tabela 2 - Fatores analisados quanto à qualidade da água, técnicas analíticas e unidades de medida.

\begin{tabular}{lcll}
\hline Variáveis & Técnica analítica & Abreviação & Unidade \\
\hline Temperatura & Termometria & Temp & ${ }^{\circ} \mathrm{C}$ \\
$\mathrm{pH}$ & Potenciometria & $\mathrm{pH}$ & Unidades de $\mathrm{pH}$ \\
Turbidez & Turbidimetria & $\mathrm{Turb}$ & $\mathrm{NTU}$ \\
Cor aparente & Espectrofotometria & $\mathrm{Cor} \mathrm{Ap}$ & $\mathrm{PtCo}$ \\
Condutividade elétrica & Condutimetria & $\mathrm{CE}$ & $\mu \mathrm{S} / \mathrm{cm}$ \\
Sólidos totais dissolvidos & Potenciometria & $\mathrm{STD}$ & $\mathrm{mg} / \mathrm{L}$ \\
Oxigênio dissolvido & Potenciometria & $\mathrm{OD}$ & $\mathrm{mg} / \mathrm{L}$ \\
Amônia & Espectrofotometria & $\mathrm{NH}$ & $\mathrm{mg} / \mathrm{L}$ \\
Nitrato & Espectrofotometria & $\mathrm{NO}{ }^{-}$ & $\mathrm{mg} / \mathrm{L}$ \\
Nitrogênio total & Digestão ácida/Titulometria & $\mathrm{NT}$ & $\mathrm{mg} / \mathrm{L}$ \\
Fósforo total & Espectrofotometria & $\mathrm{PT}$ & $\mathrm{mg} / \mathrm{L}$ \\
Material em suspensão & Gravimetria & $\mathrm{MS}$ & $\mathrm{mg} / \mathrm{L}$ \\
Demanda bioquímica de oxigênio & Automatizado/Hach & $\mathrm{DBO}$ & $\mathrm{mgO} / \mathrm{L}$ \\
& Substrato & & \\
Coliformes totais & cromogênico/fluorogênico & $\mathrm{Col} \mathrm{Tot}$ & $\mathrm{NMP} / 100 \mathrm{~mL}$ \\
Escherichia coli & Substrato & & \\
\hline
\end{tabular}

\section{4. Índice de qualidade da água (IQA)}

O IQA - Índice de Qualidade da Água - estabelecido pela Companhia Ambiental do Estado de São Paulo a partir de um estudo realizado em 1970 pela National Sanitation Foundation Institution também foi determinado neste estudo para avaliação da qualidade da água. Este índice é baseado na construção de curvas de qualidade e agregação ponderada de parâmetros selecionados: temperatura, $\mathrm{pH}$, oxigênio dissolvido, $\mathrm{DBO}$, coliformes termotolerantes (E. coli), nitrogênio total, fósforo total, sólidos (resíduos) totais e turbidez (CETESB, 2009). A equação utilizada para a determinação do IQA é:

$$
\mathrm{IQA}=\prod_{\mathrm{i}=1}^{\mathrm{n}} \mathrm{q}_{\mathrm{i}}^{\mathrm{w}_{\mathrm{i}}}
$$

onde:

IQA: Índice de Qualidade das Águas (número entre 0 e 100);

$\mathrm{q}_{\mathrm{i}}$ : qualidade do i-ésimo parâmetro, um número entre 0 e 100 obtido da respectiva curva média de variação de qualidade em função de sua concentração ou medida;

$\mathrm{W}_{\mathrm{i}}$ : peso correspondente ao i-ésimo parâmetro, um número entre 0 e 1 , atribuído em função da sua importância para a conformação global de qualidade;

i: número do parâmetro, variando de 1 a 9 (n=9; número de parâmetros que compõem o IQA). 
A partir do cálculo efetuado foi possível determinar a qualidade das águas na microbacia do rio Cabeça e classificá-las em uma escala de 0 a 100. A classificação está demonstrada na Tabela 3.

Tabela 3 - Classificação das águas segundo o IQA desenvolvido pela CETESB.

\begin{tabular}{cc}
\hline Categoria & Ponderação \\
\hline Ótima & $79<$ IQA $\leq 100$ \\
Boa & $51<$ IQA $\leq 79$ \\
Regular & $36<$ IQA $\leq 51$ \\
Ruim & $19<$ IQA $\leq 36$ \\
Péssima & IQA $\leq 19$ \\
\hline
\end{tabular}

Fonte: CETESB (2009).

\subsection{Análises estatísticas e interpretação dos dados obtidos}

Os dados obtidos para a qualidade da água foram analisados estatisticamente por meio de análise de variância fatorial, para descrever o comportamento dos parâmetros físicos, químicos e microbiológicos. O modelo de variância do tipo fatorial considerou como fatores os pontos de amostragem (7 no total) e períodos de estudo chuvoso/quente (outubro a março) e seco/frio (abril a setembro). Posteriormente, o Teste de Tukey foi aplicado para estes dois fatores quando observadas diferenças estatisticamente significativas ao nível de 5\% de significância, permitindo deste modo a comparação múltipla entre os fatores analisados. As análises estatísticas foram realizadas no software STATISTICA versão 7.1 (STATSOFT, 2005).

\section{RESULTADOS E DISCUSSÃO}

O valor máximo e mínimo, a média e desvio padrão dos fatores estudados que permitem verificar a qualidade da água em cada ponto de amostragem são apresentados na Tabela 4. A Tabela 5 apresenta o valor máximo e mínimo, a média e desvio padrão dos fatores analisados nos períodos seco/frio e chuvoso/quente.

O tempo gasto para a realização das coletas, aproximadamente 4 horas, não foi suficiente para que grandes mudanças na temperatura da água fossem observadas nos pontos amostrados, pois os valores encontrados não diferiram estatisticamente entre si (Tabela 4). Isto se deve, provavelmente, ao maior calor latente da água, que possui maior resistência às mudanças de temperatura do que a do ar.

Os menores valores de $\mathrm{pH}$ foram encontrados no ponto $\mathrm{P} 1$, próximo às nascentes do rio Cabeça, e há aumento destes à medida que os pontos de amostragem se aproximam da foz deste rio. Os pontos amostrados no rio Cabeça diferiram estatisticamente entre si (Tabela 4), indicando que provavelmente diferentes fatores ambientais, naturais ou antrópicos, estão atuando em cada um destes pontos de amostragem. Esteves (1998) destacou que o pH é considerado uma das variáveis ambientais mais importantes, mas sua interpretação é difícil devido aos inúmeros fatores que podem influenciá-lo. 
Tabela 4 - Médias, valores mínimos e máximos e desvio padrão dos fatores estudados para verificar a qualidade da água nos pontos de amostragem, nos rios Cabeça e Passa Cinco.

\begin{tabular}{|c|c|c|c|c|c|c|c|c|c|c|c|c|c|c|c|}
\hline $\begin{array}{c}\text { Pontos } \\
\text { amostrais }\end{array}$ & Temp & pH & Turb & Cor Ap & CE & STD & OD & $\mathrm{NH}_{4}$ & $\mathrm{NO}_{3}^{-}$ & NT & PT & MS & Dво & Col Tot & E. coli \\
\hline \multirow{3}{*}{ P1 } & $21,1 \mathrm{a}$ & $5,4 \mathrm{f}$ & $11,9 \mathrm{a}$ & 97,6 a & $21,3 \mathrm{~b}$ & $14,0 \mathrm{~b}$ & $8,0 \mathrm{a}$ & $0,1 \mathrm{~b}$ & $0,3 \mathrm{c}$ & $0,6 \mathrm{~b}$ & $18,9 \mathrm{~b}$ & $8,0 \mathrm{a}$ & 6,7 a & $7361 \mathrm{~b}$ & $408 \mathrm{a}$ \\
\hline & $15,9-24,4$ & $4,6-6,0$ & $5,4-57,6$ & $41,7-338,7$ & $18,3-27,0$ & $12,0-18,0$ & $5,9-9,7$ & $0,1-0,3$ & $0,2-0,5$ & $0,4-1,0$ & $3,9-51,5$ & $2,5-27,0$ & $2,2-14,8$ & $1500-27550$ & $100-2310$ \\
\hline & 2,7 & 0,3 & 11,4 & 64,5 & 2,1 & 1,6 & 0,9 & 0,1 & 0,1 & 0,1 & 11,9 & 5,9 & 3,6 & 6394 & 489 \\
\hline \multirow[t]{3}{*}{ P2 } & $21,0 \mathrm{a}$ & $5,6 \mathrm{e}$ & $20,3 \mathrm{a}$ & $144,8 \mathrm{a}$ & $26,6 \mathrm{~b}$ & $17,4 \mathrm{~b}$ & $8,4 \mathrm{a}$ & $0,1 \mathrm{~b}$ & $0,3 \mathrm{c}$ & $0,6 \mathrm{~b}$ & $38,8 \mathrm{ab}$ & $18,9 \mathrm{a}$ & $7,1 \mathrm{a}$ & $15303 \mathrm{ab}$ & $744 \mathrm{a}$ \\
\hline & $16,1-24,4$ & $5,1-6,2$ & $8,3-66,6$ & $56,0-376,0$ & $21,7-33,7$ & $14,0-23,0$ & $6,3-11,1$ & $0,02-0,2$ & $0,1-0,4$ & $0,4-0,8$ & $7,8-100,4$ & $5,5-52,5$ & $2,4-15,8$ & $2460-48840$ & $100-2110$ \\
\hline & 2,8 & 0,3 & 13,1 & 71,3 & 3,2 & 2,3 & 1,1 & 0,1 & 0,1 & 0,1 & 22,9 & 11,6 & 3,6 & 13708 & 512 \\
\hline \multirow[t]{3}{*}{ P3 } & $21,3 \mathrm{a}$ & $5,9 \mathrm{~d}$ & $24,6 \mathrm{a}$ & $185,6 \mathrm{a}$ & $32,0 \mathrm{~b}$ & $20,9 \mathrm{~b}$ & $8,3 \mathrm{a}$ & $0,1 \mathrm{ab}$ & $0,4 \mathrm{bc}$ & $0,7 \mathrm{ab}$ & $44,5 \mathrm{ab}$ & $19,6 \mathrm{a}$ & $7,4 \mathrm{a}$ & $17802 \mathrm{ab}$ & $1070 \mathrm{a}$ \\
\hline & $15,9-24,4$ & $5,0-6,4$ & $10,2-81,9$ & $74,0-506,0$ & $25,7-40,7$ & $17,0-26,7$ & $6,0-11,0$ & $0,04-0,3$ & $0,2-0,6$ & $0,4-1,1$ & $16,1-120,4$ & $5,5-62,0$ & $1,9-14,5$ & $3440-62940$ & $100-4190$ \\
\hline & 2,8 & 0,4 & 15,4 & 93,0 & 4,4 & 3,0 & 1,2 & 0,1 & 0,1 & 0,2 & 23,9 & 13,5 & 3,4 & 15262 & 828 \\
\hline \multirow[t]{3}{*}{ P4 } & $21,8 \mathrm{a}$ & $6,1 \mathrm{c}$ & $25,7 \mathrm{a}$ & $202,2 \mathrm{a}$ & $36,6 \mathrm{~b}$ & $23,7 \mathrm{~b}$ & $8,0 \mathrm{a}$ & $0,2 \mathrm{a}$ & $0,4 \mathrm{ab}$ & $0,7 \mathrm{ab}$ & $50,6 \mathrm{ab}$ & 16,4 a & $6,8 \mathrm{a}$ & $18382 \mathrm{ab}$ & 1089 a \\
\hline & $16,3-25,0$ & $5,6-6,7$ & $9,0-79,0$ & $72,0-475,7$ & $29,0-47,0$ & $19,0-31,0$ & $6,0-10,4$ & $0,07-0,4$ & $0,3-0,6$ & $0,4-1,1$ & $9,9-178,7$ & $3,5-50,5$ & $1,5-12,5$ & $3930-54750$ & $100-4570$ \\
\hline & 2,8 & 0,3 & 17,1 & 95,6 & 4,9 & 3,4 & 1,1 & 0,1 & 0,1 & 0,2 & 39,0 & 12,1 & 3,1 & 14594 & 1201 \\
\hline \multirow[t]{3}{*}{ P5 } & $21,8 \mathrm{a}$ & $6,4 \mathrm{~b}$ & $30,2 \mathrm{a}$ & $233,2 \mathrm{a}$ & $41,4 \mathrm{~b}$ & $27,0 \mathrm{~b}$ & $8,6 \mathrm{a}$ & $0,2 \mathrm{a}$ & $0,5 \mathrm{a}$ & $0,8 \mathrm{a}$ & $54,1 \mathrm{a}$ & $18,8 \mathrm{a}$ & 6,7 a & $22231 \mathrm{a}$ & 871 a \\
\hline & $16,3-25,5$ & $5,6-7,1$ & $8,6-205,3$ & $78,3-1320,0$ & $32,7-54,7$ & $21,0-35,7$ & $6,8-11,4$ & $0,06-0,4$ & $0,3-1,0$ & $0,4-1,5$ & $9,0-234,2$ & $3,0-116,0$ & $1,8-14,5$ & $2470-98040$ & $100-3690$ \\
\hline & 2,9 & 0,3 & 39,4 & 244,8 & 6,1 & 4,0 & 1,2 & 0,1 & 0,2 & 0,3 & 49,0 & 23,0 & 3,4 & 24263 & 845 \\
\hline \multirow[t]{3}{*}{ P6 } & $22,0 \mathrm{a}$ & $6,9 \mathrm{a}$ & $28,6 \mathrm{a}$ & $198,2 \mathrm{a}$ & 77,3 a & $50,2 \mathrm{a}$ & 8,5 a & $0,1 \mathrm{ab}$ & $0,4 \mathrm{~b}$ & $0,7 \mathrm{ab}$ & $58,4 \mathrm{a}$ & $22,0 \mathrm{a}$ & $7,1 \mathrm{a}$ & 23919 a & $1427 \mathrm{a}$ \\
\hline & $16,5-26,7$ & $6,4-7,5$ & $4,9-164$ & $34,3-1093,3$ & $49,7-327,3$ & $32,0-213,0$ & $6,1-11,2$ & $0,01-0,3$ & $0,2-0,9$ & $0,4-1,3$ & $4,1-222,4$ & $1,0-117,0$ & $2,0-17,3$ & $2380-82970$ & $200-9590$ \\
\hline & 3,0 & 0,3 & 40,9 & 239,8 & 56,3 & 36,6 & 1,2 & 0,1 & 0,1 & 0,2 & 55,6 & 30,3 & 3,7 & 21478 & 2168 \\
\hline \multirow[t]{3}{*}{$\mathbf{P 7}$} & $22,2 \mathrm{a}$ & $6,8 \mathrm{a}$ & $34,8 \mathrm{a}$ & $239,7 \mathrm{a}$ & $62,9 \mathrm{a}$ & $41,0 \mathrm{a}$ & 8,5 a & $0,2 \mathrm{ab}$ & $0,4 \mathrm{ab}$ & $0,7 \mathrm{ab}$ & $65,5 \mathrm{a}$ & $26,5 \mathrm{a}$ & 7,5 a & $23635 \mathrm{a}$ & $1636 \mathrm{a}$ \\
\hline & $16,5-26,3$ & $6,4-7,3$ & $6,6-269$ & $61,0-1616,7$ & $45,7-216,7$ & $29,7-141,0$ & $6,4-11,1$ & $0,03-0,3$ & $0,3-0,6$ & $0,4-1,3$ & $8,0-304,8$ & $2,0-191,5$ & $3,0-19,0$ & $2350-96060$ & $100-10810$ \\
\hline & 2,9 & 0,3 & 55,6 & 314,8 & 35,1 & 22,8 & 1,2 & 0,1 & 0,1 & 0,2 & 64,5 & 42,8 & 3,5 & 23731 & 2730 \\
\hline
\end{tabular}

Médias seguidas com a mesma letra não diferiram estaticamente entre si, de acordo com a análise de variância seguida das comparações múltiplas, ao nível de 5\% de significância.

Tabela 5 - Médias, valores mínimos e máximos e desvio padrão dos fatores estudados para verificar a qualidade da água nos pontos de amostragem, nos rios Cabeça e Passa Cinco, considerando os períodos de estudo seco/frio e chuvoso/quente.

\begin{tabular}{|c|c|c|c|c|c|c|}
\hline \multirow[b]{3}{*}{ Parâmetros } & \multicolumn{6}{|c|}{ Períodos de estudo } \\
\hline & \multicolumn{3}{|c|}{ Seco/Frio } & \multicolumn{3}{|c|}{ Chuvoso/quente } \\
\hline & Média & Min-Máx & Desvio Padrão & Média & Min-Máx & Desvio Padrão \\
\hline Temp & 19,6 a & $15,9-24,7$ & 2,5 & $23,6 \mathrm{~b}$ & $20,7-26,7$ & 1,2 \\
\hline pH & $6,0 \mathrm{a}$ & $4,6-7,1$ & 0,6 & $6,3 \mathrm{~b}$ & $5,13-7,50$ & 0,6 \\
\hline Turb & $15,7 \mathrm{a}$ & $4,9-43,0$ & 8,6 & $34,6 \mathrm{~b}$ & $5,2-269,0$ & 42,7 \\
\hline Cor Ap & $125,6 \mathrm{a}$ & $34,3-315,7$ & 57,3 & $246,5 \mathrm{~b}$ & $64-1616,7$ & 247,2 \\
\hline $\mathbf{C E}$ & 36,8 a & $18,3-64,3$ & 13,5 & $48,4 \mathrm{~b}$ & $20,0-327,3$ & 41,4 \\
\hline STD & 23,9 a & $12,0-41,7$ & 8,7 & $31,6 \mathrm{~b}$ & $13,0-213,0$ & 26,8 \\
\hline OD & $9,2 \mathrm{a}$ & $7,65-11,42$ & 0,8 & $7,5 \mathrm{~b}$ & $5,94-8,81$ & 0,6 \\
\hline $\mathbf{N H}_{4}$ & $0,1 \mathrm{a}$ & $0,01-0,3$ & 0,1 & $0,2 \mathrm{~b}$ & $0,05-0,4$ & 0,1 \\
\hline $\mathrm{NO}_{3}$ & $0,4 \mathrm{a}$ & $0,2-0,7$ & 0,1 & $0,4 \mathrm{~b}$ & $0,1-1,0$ & 0,2 \\
\hline NT & $0,6 \mathrm{a}$ & $0,4-1,1$ & 0,1 & $0,7 \mathrm{~b}$ & $0,4-1,5$ & 0,2 \\
\hline PT & $31,3 \mathrm{a}$ & $3,9-109,7$ & 23,6 & $63,2 \mathrm{~b}$ & $7,8-304,8$ & 52,6 \\
\hline MS & $10,6 \mathrm{a}$ & $1,00-45,00$ & 6,92 & $26,5 \mathrm{~b}$ & $2,0-191,5$ & 30,1 \\
\hline DBO & $6,5 \mathrm{a}$ & $1,5-19,0$ & 4,12 & $7,6 \mathrm{a}$ & $3,5-14,8$ & 2,5 \\
\hline Col Tot & 8844 a & $1500-22820$ & 5308 & $27908 \mathrm{~b}$ & $2460-98040$ & 21932 \\
\hline E. coli & $695 \mathrm{a}$ & $100-3690$ & 592 & $1374 \mathrm{~b}$ & $100-10810$ & 1974 \\
\hline
\end{tabular}

Médias seguidas com a mesma letra não diferem estaticamente entre si, de acordo com a análise de variância seguida das comparações múltiplas, ao nível de $5 \%$ de significância. 
A Resolução CONAMA 357/2005 (BRASIL, 2005) estabeleceu que para os corpos hídricos de águas doces, o pH deve estar entre os limites de 6,0 e 9,0. Valores de $\mathrm{pH}$ abaixo de 6,0 foram encontrados principalmente nos pontos P1, P2 e P3 (Tabela 4). $\mathrm{O}$ aumento do $\mathrm{pH}$ a medida que se aproxima da foz do rio Cabeça pode estar relacionado com o uso de corretivos agrícolas durante o preparo do solo para a cultura de cana-de-açúcar presente, principalmente, nas áreas adjacentes aos pontos P3, P4 e P5.

Os maiores valores de $\mathrm{pH}$ encontrados no período chuvoso/quente (Tabela 5) podem também estar relacionado à lixiviação e erosão mais intensa dos solos das áreas agrícolas, devido a maior pluviosidade. Esta ocorre principalmente na época de preparo do solo, que fica mais exposto sem cobertura vegetal. Para embasar esta possibilidade maiores valores de turbidez e cor aparente foram encontrados neste mesmo período (Tabela 5), sendo conseqüência do escoamento superficial mais intenso, introduzindo assim, maior quantidade de sedimentos nos corpos hídricos.

Quanto aos pontos de amostragem não foi verificado diferença estatisticamente significativa entre eles para estes dois parâmetros (Tabela 4). As águas do rio Cabeça contribuíram para aumentar os valores de turbidez e cor aparente do ponto P7 quando comparado aos P6, ambos no rio Passa Cinco. Este aumento, entretanto, não foi suficiente para que estes pontos apresentassem diferenças estatisticamente significativas (Tabela 4).

O limite estabelecido para turbidez pela Resolução CONAMA 357/2005 (BRASIL, 2005) para rios de classe 2 é de $100 \mathrm{UNT}$. Valores maiores que este foram observados nos pontos P5 (205,3 UNT), P6 (164,0 UNT) e P7 (269,0 UNT) em dezembro de 2007 e no P6 (148,7 UNT) e P7 (127,7 UNT) em fevereiro de 2008.

A condutividade elétrica e STD tiveram o mesmo comportamento quando analisado o fator pontos de amostragem, pois no rio Cabeça estes não apresentaram diferenças estatisticamente significativas entre si (grupo de Tukey B) da mesma forma que P6 não diferiu de P7 (grupo de Tukey A), ambos no rio Passa Cinco. Pode-se verificar, entretanto, que o ponto P7 apresentou valores menores do que o $\mathrm{P} 6$ para os dois parâmetros, muito provavelmente devido à diluição provocada pelas águas do rio Cabeça ao desaguarem neste outro rio (Tabela 4). No período chuvoso/quente foram observadas maiores médias para condutividade elétrica e STD decorrente do carreamento de íons e sedimentos juntamente com o escoamento superficial. Nenhum valor encontrado para STD foi superior aquele estabelecido pela Resolução CONAMA 357/2005 (BRASIL, 2005), que estabeleceu um limite máximo de $500 \mathrm{mg} . \mathrm{L}^{-1}$ para corpos hídricos de classe 2.

A Tabela 4 mostra que o período seco/frio apresentou maior média para o parâmetro OD. Isso é explicado pelas temperaturas mais amenas nesta estação que contribuiu para a maior solubilidade desse gás na água. Os valores de OD encontrados nos pontos de amostragem não apresentaram diferença estatisticamente significativa entre si (Tabela 4). Nenhum valor deste parâmetro esteve abaixo do limite preconizado pela Resolução CONAMA 357/2005 (BRASIL, 2005) para corpos hídricos de classe 2 , ou seja, 5,0 mg. $\mathrm{L}^{-1}$. O rio Cabeça é um corpo hídrico que apresenta cachoeiras, quedas e corredeiras, as quais são responsáveis pelo turbilhonamento das águas em alguns trechos permitindo a oxigenação mecânica, sendo este um dos fatores que explicam os valores de OD observados.

Os maiores valores de amônia ocorreram nos pontos P4 e P5. Estes pontos diferiram estatisticamente dos pontos P1 e P2 (Tabela 4). Os valores de amônia encontrados nos pontos de amostragem foram inferiores àquele limite permitido pela Resolução CONAMA 357/2005 (BRASIL, 2005), que estabeleceu um limite máximo de 3,7 mg.L $\mathrm{L}^{-1}$, para $\mathrm{pH} \leq 7,5$. A amônia representa a forma primária do nitrogênio logo após a degradação dos compostos nitrogenados, componentes das proteínas e aminoácidos, sendo oxidada a nitrito e, posteriormente, a nitrato. Dessa forma a sua presença permite identificar fontes orgânicas poluidoras recentes.

Ao analisar o nitrato verifica-se que os pontos P4, P5, P6 e P7, cujas áreas adjacentes há o predomínio de cana-de-açúcar, diferiram estatisticamente de P1 e P2, onde nessas áreas ocorre a 
pastagem. Os maiores valores encontrados naqueles pontos indicam uma possível interferência da cultura canavieira na determinação deste parâmetro. O ponto P3 se destaca por apresentar pastagem e cana-de-açúcar em suas áreas adjacentes e não diferiu estatisticamente de P1, P2 e P4 (Tabela 4). Os resultados obtidos nos períodos seco/frio e chuvoso/quente também apresentaram diferenças estatisticamente significativas entre si (Tabela 5), indicando que as altas pluviosidades podem contribuir para introdução de nitrato nas águas dos corpos hídricos estudados. A Resolução CONAMA 357/2005 (BRASIL, 2005) estipulou valor máximo de 10,0 mg.L.-1 para rios de classe 2. Os valores encontrados não ultrapassaram este limite.

O nitrogênio, sendo fator limitante, é importante do ponto de vista sanitário, já que ao ser incrementado em qualquer água, traz aumento da proliferação de algas e cianobactérias que podem aumentar a DBO do sistema. O ponto P5 apresentou maior média sendo esta estatisticamente diferente das médias observadas nos pontos P1 e P2 (Tabela 4). As maiores médias deste parâmetro encontradas no período chuvoso/quente estão relacionadas com o escoamento superficial mais intenso característico desse período (Tabela 5), já citado anteriormente.

A Resolução CONAMA 357/2005 (BRASIL, 2005) estabeleceu o limite de 0,1 mg.L.-1 de fósforo total para ambiente lótico e tributários de ambientes intermediários pertencentes a classe 2 . Valores acima deste foram observados nos pontos P3 (4,2\% das amostras), P4, P5 e P6 (12,5\% das amostras de cada ponto) e P7 (8,3\% das amostras). Ainda analisando o fósforo total, a comparação múltipla dos pontos de amostragem revelou que o ponto P1 diferiu estatisticamente de P5, P6 e P7 (Tabela 4). Também houve diferença estatisticamente significativa entre os períodos de estudo, sendo que no período chuvoso/quente as médias observadas foram aproximadamente duas vezes maiores do que as encontradas no período seco/frio (Tabela 5), conseqüência provável do arraste mais intenso deste elemento principalmente de áreas cultiváveis, a semelhança do que ocorre com outros compostos.

Os pontos de amostragem não diferiram estatisticamente entre si quando foi analisado o material em suspensão (Tabela 4). A maior média para este parâmetro foi encontrada no período chuvoso/quente (Tabela 5), também devido ao escoamento superficial mais intenso. Diversos trechos do rio Cabeça não possuem mata ciliares conservadas e apresentam-se assoreados. Em alguns pontos observou-se que a cana-de-açúcar substituiu este tipo de vegetação.

A análise de variância para DBO demonstrou que os dois fatores analisados, pontos de amostragem e períodos de estudo, não apresentaram diferenças estatisticamente significativas (Tabelas 4 e 5). A Resolução CONAMA 357/2005 (BRASIL, 2005) estabeleceu limites para a DBO que não deve ultrapassar $5 \mathrm{mg} . \mathrm{L}^{-1}$ para os rios de classe 2. Verificou-se que para os pontos $\mathrm{P} 1$ e P2, $63 \%$ das amostras apresentaram valores superiores a este limite, enquanto que $67 \%, 67 \%$ e $71 \%$ das amostras respectivamente para os pontos P4, P5 e P6, estiveram em desacordo com a legislação vigente. Os pontos P3 e P7 foram os que apresentaram maior frequência de valores fora do limite para este parâmetro, sendo $75 \%$ das amostras em cada ponto. Desta forma, estes resultados desenquadram o rio Cabeça e Passa Cinco da classe 2 podendo estes corpos hídricos serem reenquadrados na classe 3 , cujo limite é $10 \mathrm{mg} . \mathrm{L}^{-1}$ ou até mesmo classe 4 , pois alguns valores ultrapassaram este valor.

Analisando coliformes totais, a comparação múltipla através do teste de Tukey (Tabela 4) dos resultados encontrados mostrou que o ponto P1 diferiu dos P5, P6 e P7, estatisticamente. Os maiores valores obtidos para coliformes totais no período chuvoso/quente também pode ser em decorrência ao escoamento superficial mais intenso, fator que contribui para a modificação da qualidade microbiológica das águas superficiais, uma vez que aumenta a taxa de sedimentos e excretas de animais e humanas carreados para o leito do rio.

Os valores encontrados de E. coli nos pontos P3, P4, P5, P6 e P7 estão em desacordo com o estabelecido na legislação, pois $67 \%, 63 \%, 75 \%, 58 \%$ e $67 \%$ das amostras analisadas, respectivamente, não excederam o limite de $1000 \mathrm{E}$. coli por $100 \mathrm{~mL}$, sendo que para se adequarem 
à Resolução CONAMA 357/2005, no mínimo 80\% das amostras não deveriam ultrapassar este limite. Estes resultados podem decorrer do lançamento de esgoto in natura das vilas e moradias rurais uma vez que esta é uma microbacia tipicamente rural. Atividades típicas na região como a criação de animais (bovinos e suínos) também podem contribuir com o aumento de $E$. coli nas águas do rio Cabeça.

A partir dos parâmetros indicados pela CETESB, o IQA foi calculado (Figura 2). A qualidade da água no rio Cabeça foi considerada boa com valores que variaram de 55 a 74 no ponto P1; 55 a 74 no P2; 56 a 77 no P3; 56 a 75 no P4 e 50 a 77 no P5. Neste último ponto a qualidade da água foi considerada regular (IQA $=50)$ em dezembro de 2007. Nos pontos amostrados no rio Passa Cinco, o IQA seguiu o mesmo padrão do rio Cabeça com águas sendo classificadas como boa, com exceção dos meses de dezembro de 2007 e fevereiro de 2008 cujas qualidades das águas foram classificadas como regulares. Os valores nestes pontos variaram de 48 a 75 no P6 e 46 a 76 no P7.

Os valores de IQA obtidos também foram submetidos à análise de variância fatorial e os resultados mostraram que para ambos os fatores, pontos de amostragem e períodos de estudo, não foram verificadas diferenças estatísticas significativas a 5\% de significância, pois $p>0,05$ (Tabela $5)$.

Vale destacar que o IQA não leva em consideração parâmetros relacionados à toxicidade e mutagenicidade das águas. Na bacia do rio Corumbataí, os estudos realizados por Armas et al. (2005) e Armas et al. (2007) concluíram que há grande risco de poluição hídrica decorrente do uso de agrotóxicos e da expansão da cultura canavieira na região norte da bacia e nas microbacias do Ribeirão Claro e rio Passa Cinco. Esta última tendo contribuição da microbacia do rio Cabeça provocaria maior aporte de herbicidas aos corpos hídricos. Para a microbacia do rio Cabeça testes de toxicidade e mutagenicidade nos corpos hídricos são de extrema valia devido à intensa aplicação de agrotóxicos. A investigação destas substâncias também é indicada, pois assim tais informações permitirão uma gestão hídrica mais eficiente na região.

A microbacia do rio Cabeça sofre diversos impactos relacionados ao uso da terra sendo identificada a presença da cultura canavieira em áreas com declives acima de $45^{\circ}$ e a ausência de vegetações protegidas por lei, no caso a mata ciliar, que em alguns casos foi substituída pela canade-açúcar. A atividade de pastagem também dificulta a regeneração da vegetação que protege os corpos hídricos devido o pisoteamento dos animais. 

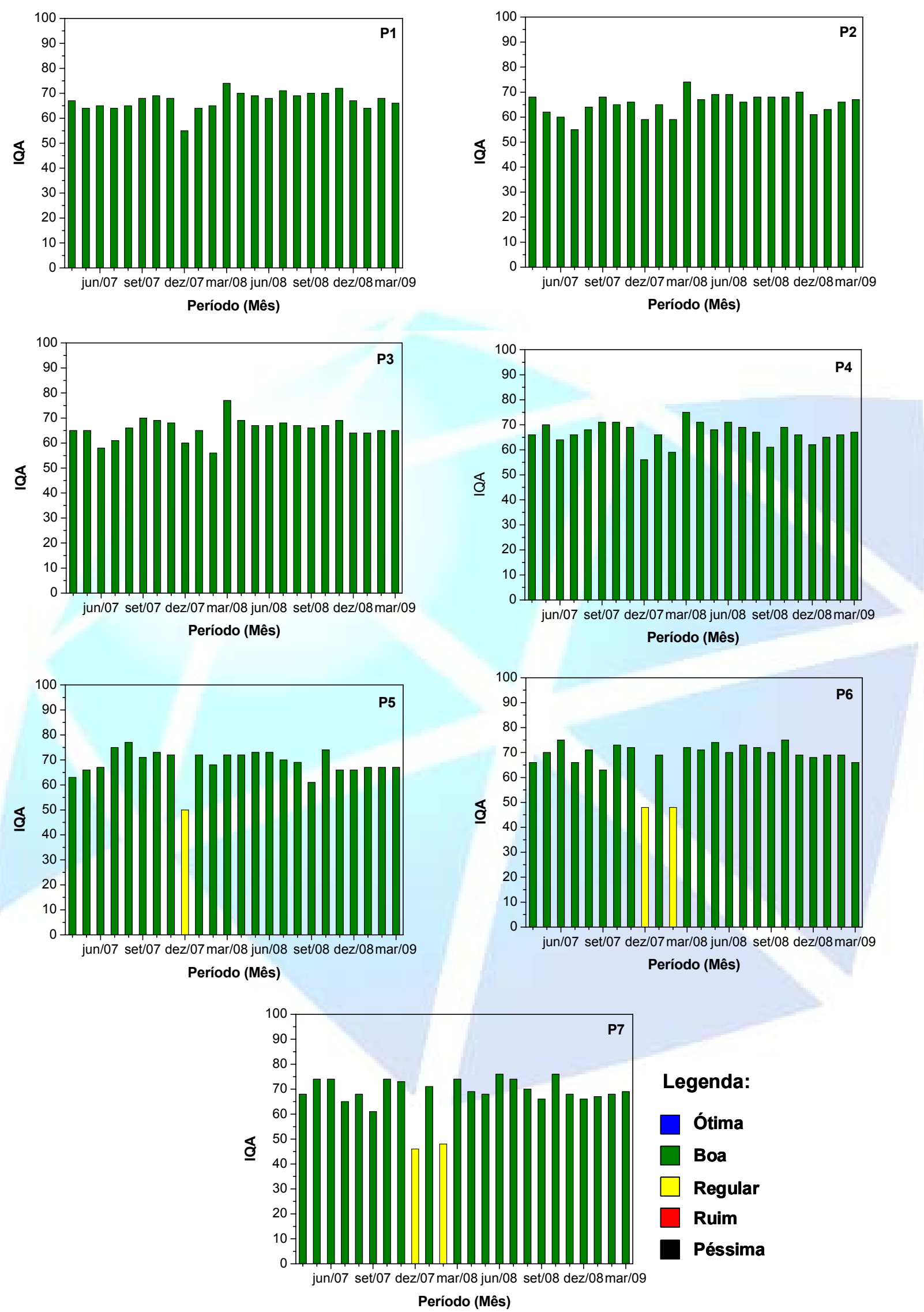

Figura 2. Índice de qualidade da água (IQA) determinado nos pontos de amostragem durante o período de abril de 2007 a março de 2009. 


\section{CONCLUSÕES}

A análise do IQA na microbacia do rio Cabeça mostrou que nesta a qualidade da água é considerada boa. Os valores, entretanto, de DBO e Escherichia coli, que são utilizados no cálculo deste índice, indicam que há poluição por efluentes domésticos das vilas rurais e/ou derivados da criação de animais e desenquadram o rio Cabeça da classe 2, segundo a Resolução do CONAMA 357/2005 (BRASIL, 2005). Assim considera-se que as águas do rio Cabeça são impróprias para o desenvolvimento de atividades previstas para rios de classe 2 como a dessedentação de animais, irrigação de hortaliças e plantas frutíferas e recreação de contato primário. Atividades de aquicultura e pesca muito comum na bacia do rio Corumbataí, também estão prejudicadas. Os resultados demonstram as limitações da utilização do IQA, que é um índice que não contempla parâmetros como metais pesados e compostos orgânicos com potencial tóxico e mutagênico como é o caso dos pesticidas, estes utilizados intensamente na área de estudo.

Como conseqüência da ausência da mata ciliar muitos trechos do rio Cabeça estão assoreados o que representa riscos para a quantidade de água deste corpo hídrico e também para sua qualidade, pois foi detectado que no período chuvoso/quente, com exceção do parâmetros DBO, os demais parâmetros qualitativos da água estudados sofrem influência do escoamento superficial mais intenso característicos deste período.

\section{AGRADECIMENTOS}

Os autores agradecem a Coordenação de Aperfeiçoamento de Pessoal de Nível Superior (CAPES) pela concessão de bolsa de doutorado ao primeiro autor.

\section{REFERÊNCIAS}

\section{APHA - AMERICAN PUBLIC HEALTH ASSOCIATION. Standard methods for the} examination of water and wastewater. 20 ed. Washington: American Public Health Association, AWWA, WPCF, 1998. 1569p.

ARMAS, E. D.; MONTEIRO, R. T. S.; AMÂNCIO, A. V.; CORREA, R. M. L.; GUERCIO, M. A. Uso de agrotóxicos em cana-de-açúcar na bacia do rio Corumbataí e o risco de poluição hídrica.

Química Nova, São Paulo, v.28, n.6, p.975-982, 2005.

ARMAS, E. D.; MONTEIRO, R. T. R.; ANTUNES, P. M.; SANTOS, M. A. P. F.; CAMARGO, P. B. Diagnóstico espaço-temporal da ocorrência de herbicidas nas águas superficiais e sedimentos do rio Corumbataí e principais afluentes. Química Nova, v.30, n.5, p.1119-1127, 2007.

BOUZA-DEAÑO, R.; TERNERO-RODRÍGUEZ, M.; A.J. FERNÁNDEZ-ESPINOSA, A. J. Trend study and assessment of surface water quality in the Ebro River (Spain). Journal of Hydrology, v.361, p.227-239. 2008.

BRASIL. Resolução no 357, 17 março de 2005. Dispõe sobre a classificação dos corpos de água e diretrizes ambientais para o seu enquadramento, bem como estabelece as condições e padrões de lançamento de efluentes, e dá outras providências. Resoluções do CONAMA - Conselho Nacional do Meio Ambiente - Ministério do Meio Ambiente -. Brasília, DF; SEMA, 2005. 23p. Disponível em $<$ http://www.mma.gov.br/port/conama/res/res05/res35705.pdf $>$. Acesso em 28 mai 2009. 
CETESB - COMPANHIA DE TECNOLOGIA E SANEAMENTO AMBIENTAL. Relatório de qualidade das águas interiores do estado de São Paulo 2008. São Paulo: CETESB, 2009. 528p.

CETRA, M.; PETRERE JR, M. Associations between fish assemblage and riparian vegetation in the Corumbataí River Basin (SP). Brazilian Journal of Biology. v.67, n.2, p.191-195, 2007.

COMIM, F. H.; GHELER-COSTA, C.; VERDADE, L. M.; GARAVELLO, M. E. P. E. Relações e conflitos na conservação ambiental da bacia do rio Passa-Cinco - São Paulo, Brasil. OLAM Ciência \& Tecnologia, Rio Claro, v.9, n.2, p.254-274, 2009.

ESTEVES, F. A. Fundamentos de limnologia. Rio de Janeiro: Interciência, 1998. 602p.

GARCIA, G. J.; GAMERO H. G.; GARCIA, L. B. R.; VETTORAZZI, C. A.; KRÖENERT, R.; VOLK, M.; LAUCH, A.; MEYER, B. Impacto do uso da terra na erosão do solo e no balanço e qualidade de água na bacia do rio Corumbataí, SP. Holos Environment. Rio Claro, v.6, n.2, p.118$136,2006$.

GERTEL, P.; TAUK-TORNISIELO, S. M.; MALAGUTTI, E. N. Qualidade das águas dos córregos São Joaquim e Ribeirão Claro, bacia do rio Corumbataí, SP. Holos Environment. Rio Claro, v.3, n.2, p.103-119, 2003.

HENRY-SILVA G. G.; CAMARGO, A. F. M. Impacto do lançamento de efluentes urbanos sobre alguns ecossistemas aquáticos do município de Rio Claro-SP. PUC-SP Ciências Biológicas e do Meio Ambiente. São Paulo, v.2, n.3, p.317-330, 2000.

MONTEIRO, C. A. F. A dinâmica climática e as chuvas no estado de São Paulo. São Paulo: USP - Instituto de Geografia, 1973. 130p.

MORAIS, E. B. Indicadores microbiológicos, metais e índice de qualidade da água (IQA) associados ao uso e ocupação da terra para avaliação da qualidade ambiental da microbacia do rio Cabeça, na bacia do rio Corumbataí, SP. 2010. 138f. Tese (Doutorado em Ciências Biológicas) - Área de Concentração em Microbiologia Aplicada, Instituto de Biociências, Universidade Estadual Paulista, Rio Claro, 2010.

NIKAIDO, M.; OLIVEIRA, A. S.; TREVILATO, T. M. B.; SEGURA-MUÑOZ, S. I. Análise da qualidade da água do córrego Monte Alegre e afluentes, Ribeirão Preto, SP: enfoque para coliformes fecais e metais pesados. O mundo da Saúde. São Paulo, v.28, n.4, p.414-420, 2004.

PALMA-SILVA, G. M.; TAUK-TORNISIELO, S. M.; PIÃO, A. C. Capacidade de autodepuração de um trecho do rio Corumbataí, SP, Brasil. Holos Environment, Rio Claro, v.7, n.2, p.139-153, 2007.

PINTO, A. L.; MAURO, C.A.A. A importância do Ribeirão Claro para o abastecimento de água da cidade de Rio Claro, SP. Boletim de Geografia Teorética. Rio Claro, v.15, n.29-30, p.115-127, 1985.

STATSOFT. STATISTICA - Data analysis software system. Version 7.1. www.statsoft.com, 2005. 